\title{
The skin as an endocrine organ
}

\author{
Christos C. Zouboulis
}

Departments of Dermatology, Venereology, Allergology and Immunology; Dessau Medical Center; Dessau, Germany; and Laboratory of Biogerontology, Dermato-Pharmacology and Dermato-Endocrinology; Institute of Clinical Pharmacology and Toxicology; Charité Universitaetsmedizin Berlin; Berlin, Germany

Key words: skin, human, hormone, dermatology, endocrinology, skin physiology

Through the definition of novel biological activities of hormones and their diversity on different skin cell types, it has become apparent that the skin itself possesses the capacity to generate several hormones and substances with hormone-like activity. These substances appear to act through paracrine, autocrine, intracrine and endocrine mechanisms to fulfill their pleiotropic effects. Also new is the knowledge that the skin can metabolize hormones and produce derivatives with potentially systemic activity. These findings point towards novel concepts in our understanding of the role of skin and of its hormones as important players in homeostasis and disorders of the entire human organism. Finally, the scientists active in the field of dermato-endocrinology expect that their activities will exploit the pharmacological and therapeutic function of hormone mediators, their receptors and antagonists. The latter idea has already been realized for corticosteroids, androgens, estrogens, topical vitamin $\mathrm{D}$ analogues and retinoids which have today an established place in clinical dermatology.

\section{Skin and Hormones}

The historical picture of the endocrine system as a set of certain hormone-producing organs has been nowadays substituted by the concept of organized communities of organs in which the cells emit, receive and coordinate molecular signals from distant sources - such as the established endocrine organs - their neighbors, and themselves (Fig. 1). Complex endocrine mechanisms, such as expression and function of specific hormone receptors, synthesis of hormones from major classes of compounds used by the body for general purposes, elimination of the hormones in specialized skin cells, and exertion of biological activity have also been identified in the skin. ${ }^{1}$

Despite this knowledge, attention to the ability of human skin to fulfill the current requirements of the functions of an endocrine organ has only been drawn lately. ${ }^{2-5}$ The human skin has been classically regarded as the target for several hormones, whose effects have long been recognized and in some instances well characterized. For example, hair follicles and sebaceous glands are the targets for androgen steroids secreted by the gonads and the adrenal cortex. ${ }^{6,7}$ In addition, hormones play an important role in

Correspondence to: Christos C. Zouboulis; Email: christos.zouboulis@

klinikum-dessau.de

Submitted: 01//6/09; Accepted: 07/13/09

Previously published online:

www.landesbioscience.com/journals/dermatoendocrinology/article/9499 the development and the physiological function of human skin tissues, ${ }^{8,9}$ and, moreover, hormones are also produced in the skin. For example, the circulating androgens dehydroepiandrosterone (DHEA) and androstenedione are converted in the skin through different pathways to testosterone or androstenedione and further to in the periphery more potent androgen $5 \alpha$-dihydrotestosterone (5a-DHT). ${ }^{10,11}$ Thus, from the modern dermato-endocrinologic point of view the skin is not only the recipient of signals from distant transmitters but is also an endocrine organ. ${ }^{12,13}$ New knowledge has rapidly accumulated in the last years on expression and function of specific hormone receptors,${ }^{14}$ synthesis of hormones from major classes of compounds used by the body for general purposes, ${ }^{15}$ organized metabolism, ${ }^{10,11}$ activation, inactivation and elimination of the hormones in specialized cells of the skin, ${ }^{16}$ exertion of biological activity, ${ }^{7,17}$ and release of tissue hormones in the circulation. ${ }^{15,17}$

\section{Hormone Receptors in Human Skin}

Hormones exert their biological effects on skin cells through binding and interaction with high-affinity receptors. The human skin expresses receptors for peptide hormones and neurotransmitters, which are mostly aligned on the cell surface, and those for steroid and thyroid hormones, which are found in the cytoplasm or nuclear compartments. . $7,15,18-20^{2}$

\section{Hormone Activity on Human Skin}

Hormones exhibit pleiotropic biologic effects on the skin and appear to act through paracrine, autocrine, intracrine and endocrine mechanisms. ${ }^{1,12}$ Particularly, growth hormone/insulin-like growth factor-1, neuropeptides, sexual steroids, glucocorticoids, retinoids, vitamin $\mathrm{D}$, peroxisome proliferator-activated receptor ligands and eicosanoids are major examples of hormones been active on the skin. ${ }^{1,14}$

\section{Hormone Synthesis in Human Skin}

Human skin produces hormones which are released in the circulation and are important for functions of the entire human organism. ${ }^{21}$ Major examples are sex steroids, whereas a large proportion of androgens and estrogens in men and women are synthesized locally in peripheral target tissues from the inactive adrenal precursors DHEA and androstenedione. ${ }^{10,11,16}$ DHEA and androstenedione are converted to testosterone or to $5 \alpha$-DHT by different pathways through the involvement of the three 


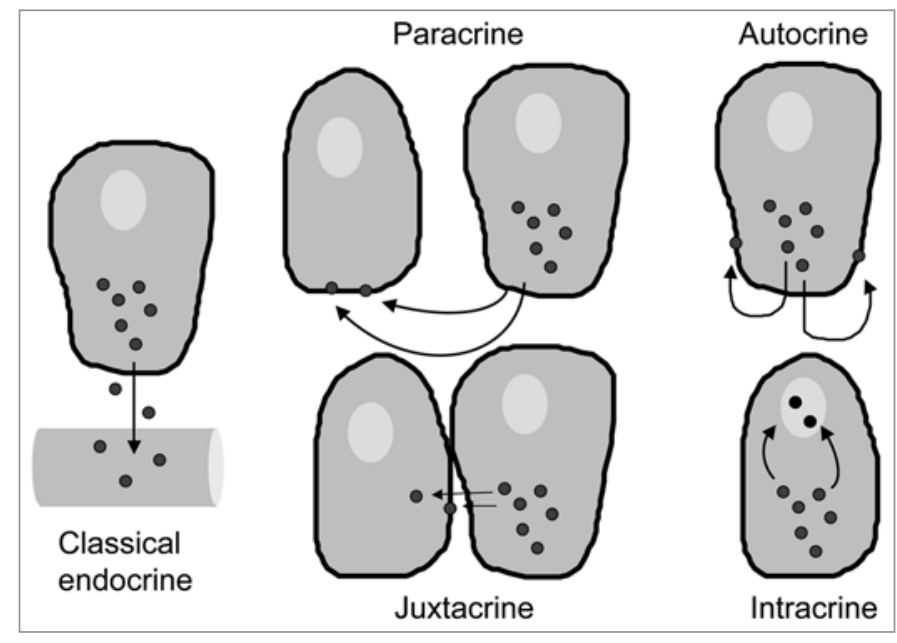

Figure I. Modes of hormone action. Classical and modern endocrine functions: Hormones produced by established endocrine organs or other distant sources, respectively, reach target tissues through the circulation. Paracrine function: Hormones act locally on cells other than those that produce them. Juxtacrine function: Hormones produced in one cell interact directly with a receptor of an immediate neighboring cell. Autocrine function: Hormones act on the cell in which they are produced. Intracrine function: Hormones get activated in the cell in which they are produced and act on it by binding to nuclear receptors.

isotypes of the intracellular enzyme $5 \alpha$-reductase and of the isotypes of $17 \beta$-hydroxysteroid dehydrogenase, ${ }^{11,16}$ thus making the skin responsible for considerable amounts of the circulating $5 \alpha$-DHT levels. The best estimate of the intracrine formation of estrogens in peripheral tissues in women is in the order of $75 \%$ before menopause and close to $100 \%$ after menopause, except for a small contribution from ovarian and/or adrenal testosterone and androstenedione. ${ }^{12}$ Thus, in postmenopausal women, almost all active sex steroids are made in target tissues by an intracrine mechanism.

Moreover, insulin-like growth factor (IGF)-binding protein-3 message levels are greater in the skin that in the liver and circulating IGF-binding protein-3 concentrations are significantly increased by growth hormone and IGF-1. ${ }^{22} \mathrm{GH}$ has a direct function in the regulation of IGF-binding protein-3 synthesis, and the response of skin IGF-binding protein-3 mRNA levels to both GH and IGF-I suggests that dermal fibroblasts could be more

\section{References}

1. Zouboulis CC. The human skin as a hormone target and an endocrine gland. Hormones 2004; 3:9-26.

2. Zouboulis CC. (ed) Basic Research in Endocrine Dermatology. $3^{\text {rd }}$ Teupitzer Colloquium 2000, Teupitz, September 17-20, 2000. Horm Res 2000; 54:213-350.

3. Zouboulis CC, Degitz K. Androgen action on human skin-From basic research to clinical significance. Exp Dermatol 2004; 13:5-10.

4. Böhm M, Zouboulis CC. (eds) DermatoEndocrinology. Exp Dermatol 2004; 13:3-40.

5. Zouboulis CC, Bornstein SR. (eds) Endocrinology of the Skin. Horm Metab Res 2007; 39:69-172.

6. Zouboulis CC, Picardo M, Reichrath J. (eds) The sebaceous glad and the pilosebaceous unit as an endocrine organ. Dermato-Endocrinology 2009; 1:63107. important than the liver in the regulation of circulating reservoir IGF-binding protein-3 in certain circumstances.

At last but not least, human skin produces hormones which are released in the circulation and are permanently important for functions of the entire human organism, such as vitamin D. ${ }^{15}$ The skin is the unique site of cholecalciferol synthesis, ${ }^{23,24}$ which derives from cholesterol. Epidermal keratinocytes contain both the machinery needed to produce calcitriol and vitamin D receptor. ${ }^{15,25}$

\section{Activation and Inactivation of Hormones in Human Skin}

In addition to its capacity to produce hormones the human skin is able to metabolize hormones in order to activate and inactivate them. These steps are overtaken in most cases by different skin cell populations in a coordinated way indicating the endocrine autonomy of the skin. Characteristic examples for this kind of endocrine skin function are the metabolic pathways of the corticotrophin-releasing hormone/propiomelanocortin axis, sex steroids, vitamin D and retinoids. ${ }^{1,15,26}$

\section{Co-Morbidities}

Cardiovascular diseases due to atherosclerosis, being the commonest cause of mortality and morbidity in the western world, is directly related to disorders of lipid metabolism, diabetes mellitus and insulin resistance. Disorders of thyroid function and porphyrin metabolism occur less frequently but may cause life-threatening situations if not recognized. All these, at least partially, endocrinological disorders are associated with characteristic dermatoses, which should permit early diagnosis and meaningful intervention..$^{27-30}$ Dermato-endocrinology seems to be wider than considered, even by those, who have initiated the field.

\section{Endocrinologically Active Compounds}

Treatment of skin diseases with with hormone mediators, of their receptors and antagonists is a common procedure in dermatology. Corticosteroids, androgens, estrogens, topical vitamin $\mathrm{D}$ analogues and retinoids have today an established place in dermato-pharmacology. $13,15,18$
7. Zouboulis CC, Chen W, Thornton MJ, Qin K, Rosenfield RL. Sexual hormones in human skin. Horm Metab Res 2007; 39:85-95.

8. Deplewski D, Rosenfield RL. Role of hormones in pilosebaceous unit development. Endocrine Rev $2000 ; 21: 363-92$

9. Stenn KS, Paus R. Control of hair follicle cycling. Physiol Rev 2001; 81:449-94.

10. Chen W, Tsai S-J, Tsai J-C, Zouboulis CC. Testosterone synthesized in cultured human SZ95 sebocytes mainly derives from dehydroepiandrosterone. Br J Dermatol 2009; 161:674-7.

11. Samson M, Labrie F, Zouboulis CC, Luu-The V. Biosynthesis of dihydrotestosterone by a pathway that does not require testosterone as intermediate in the SZ95 sebaceous gland cell line. J Invest Dermatol 2009; In press.
12. Labrie F, Luu-The V, Labrie C, Pelletier G, El-Alfy M. Intracrinology and the skin. Horm Res 2000; 54:218-29.

13. Orfanos CE, Adler YD, Zouboulis CC. The SAHA syndrome. Horm Res 2000; 54:251-8.

14. Zouboulis CC. Sebaceous gland receptors. DermatoEndocrinology 2009; 1:77-80.

15. Reichrath J, Lehmann B, Carlberg C, Varani J, Zouboulis CC. Vitamins as hormones. Horm Metab Res 2007; 39:71-84.

16. Fritsch M, Orfanos CE, Zouboulis CC. Sebocytes are the key regulators of androgen homeostasis in human skin. J Invest Dermatol 2001; 116:793-800.

17. Krämer C, Seltmann H, Seifert M, Tilgen W, Zouboulis CC, Reichrath J. Characterization of the vitamin $\mathrm{D}$ endocrine system in human sebocytes in vitro. J Steroid Biochem Mol Biol 2009; 113:9-16. 

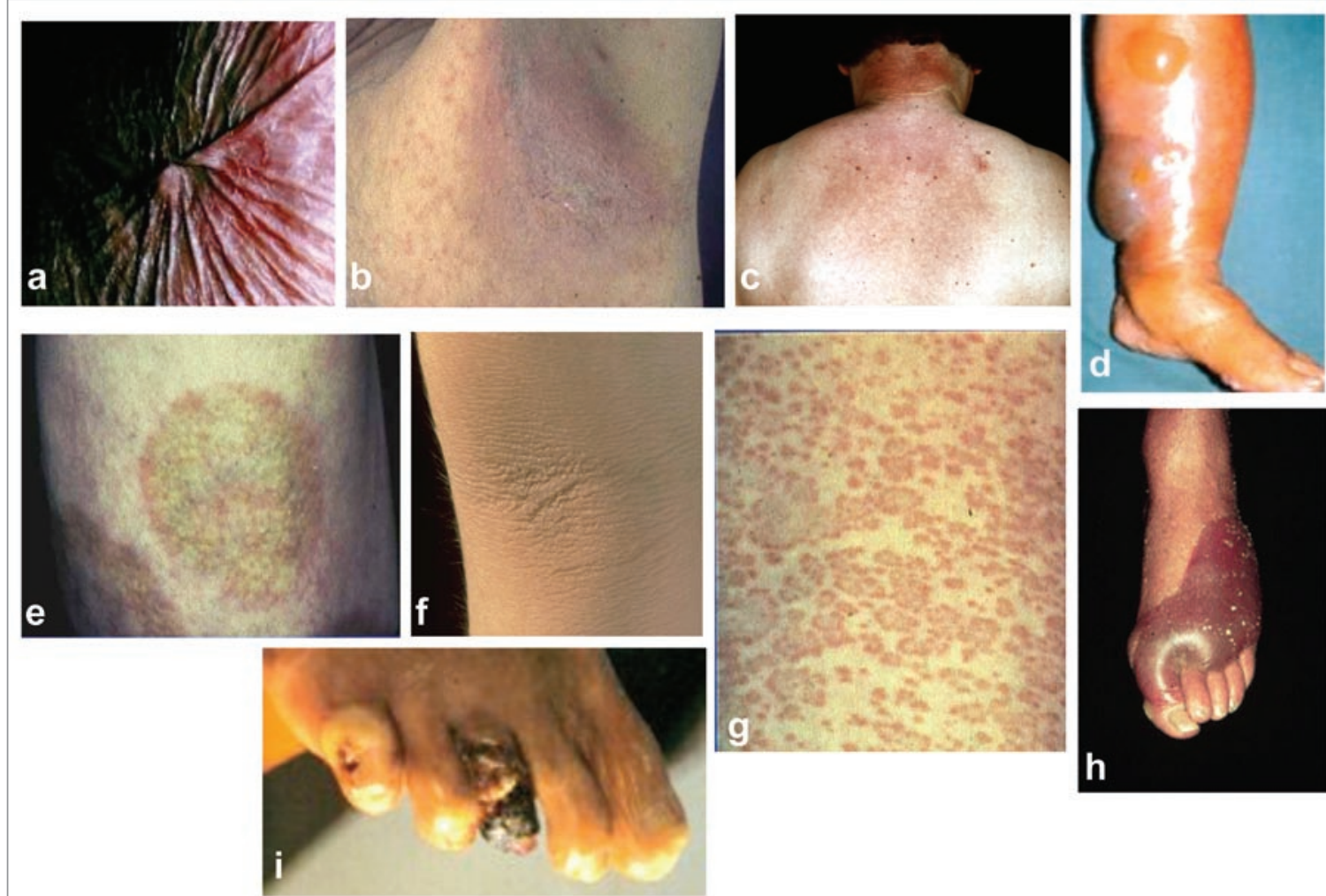

Figure 2. Skin diseases and manifestations associated with diabetes mellitus. (a) skin atrophy, (b) candida-induced intertrigo, (c) scleromyxedema Arndt-Gottron, (d) bullosis diabeticorum, (e) necrobiosis lipoidica, (f) acanthosis nigiricans, (g) granuloma anulare disseminatum, (h) bullous hemorrhagic erysipelas (i) peripheral vascular necrosis (gangraine).

18. Chen W, Thiboutot D, Zouboulis CC. Cutaneous androgen metabolism-Basic research and clinical perspectives. J Invest Dermatol 2002; 119:992-1007.

19. Chen W, Zouboulis CC. Hormones and the pilosebaceous unit. Dermato-Endocrinology 2009; 1:81-6.

20. Schmuth M, Watson REB, Deplewski D, Dubrac S, Zouboulis CC, Griffiths CEM. Nuclear hormone receptors in human skin. Horm Metab Res 2007; 39:96-105.

21. Cao T, Tsai SY, O’Malley BW, Wang XJ, Roop DR. The epidermis as a bioreactor: topically regulated cutaneous delivery into the circulation. Hum Gene Ther 2002; 13:1075-80.

22. Lemmey AB, Glassford J, Flick-Smith HC, Holly JM, Pell JM. Differential regulation of tissue insulin-like growth factor-binding protein (IGFBP)-3, IGF-I and IGF type 1 receptor mRNA levels, and serum IGF-I and IGFBP concentrations by growth hormone and IGF-I. J Endocrinol 1997; 154:319-28.
23. Schuessler M, Astecker N, Herzig G, Vorisek G, Schuster I. Skin is an autonomous organ in synthesis, two-step activation and degradation of vitamin $\mathrm{D}(3)$ : CYP27 in epidermis completes the set of essentia vitamin D(3)-hydroxylases. Steroids 2001; 66:399408.

24. Lehmann B, Knuschke P, Meurer M. A novel pathway for hormonally active calcitriol. Horm Res 2000 ; 54:312-5.

25. Adorini L. Immunomodulatory effects of vitamin $\mathrm{D}$ receptor ligands in autoimmune diseases. Int Immunopharmacol 2002; 2:1017-28.

26. Zouboulis CC, Böhm M. Neuroendocrine regulation of sebocytes-a pathogenetic link between stress and acne. Exp Dermatol 2004; 13:31-5.

27. Pitambe HV, Schulz EJ. Life-threatening dermatoses due to metabolic and endocrine disorders. Clin Dermatol 2005; 23:258-66
28. Zouboulis CC, Blume-Peytavi U, Lennert T, Stavropoulos PG, Schwarz A, Runkel N, et al. Fulminant metastatic calcinosis with cutaneous necrosis in a child with end-stage renal disease and tertiary hyperparathyroidism. Brit J Dermatol 1996; 135:617-22.

29. Adler YD, Zouboulis CC, Geilen CC, Orfanos CE. Eine seltene Variante des SAHA Syndroms. Z Hautkr $2000 ; 76: 327-8$.

30. Steinhoff M, Rochlitz H, Nussbaum G, Georgieva J, Zouboulis CC. Reduced growth of beard as the only diagnostic sign in a patient with macroprolactinoma. J Eur Acad Dermatol Venereol 2007; 21:124-6. 